\title{
Análise das intoxicações por agrotóxicos de uso agrícola no Brasil entre 2009 e 2014
}

Em grande parte das produções agrícolas brasileiras, os agrotóxicos têm sido amplamente utilizados para a proteção de lavouras e controle de pragas. São tão utilizados que há muita discussão sobre o seu uso abusivo, e as consequências de sua utilização para o organismo humano. O Brasil tornou-se o maior consumidor de agrotóxicos no mundo, dentre eles herbicidas, inseticidas e fungicidas. Os agrotóxicos organofosforados, com destaque aos glifosatos, são os mais utilizados nas produções brasileiras e o alvo de diversos estudos sobre sua toxicidade, uma vez que diversas patologias estão relacionadas à exposição direta ou indireta a esses produtos. Este artigo tem como objetivo realizar uma análise do consumo de agrotóxicos no Brasil, as principais relações com a saúde e, através de dados de uso de agrotóxicos categoria uso agrícola, apresentar dados sobre o número de intoxicação, visando detalhar o quão nocivo o uso contínuo de agrotóxicos contribui para os gastos com saúde pública. A metodologia consistiu no levantamento de dados abertos do IBGE, SINAN e SINITOX para realização de análise temporal. Verificou-se que a classe III de periculosidade foi a mais utilizada e o glifosato e seus sais são os ingredientes ativos mais aplicados. Quanto às intoxicações, houve diminuição nos registros de casos, porém, observa-se que ainda existem muitas subnotificações no país. Notou-se também que, para que eventos como esses tenham redução, é indispensável a execução de políticas públicas para o incentivo de produção orgânica e agroecológica, contribuindo para a melhor qualidade de vida para todos os que trabalham e consomem os produtos advindos dessas produções.

Palavras-chave: Glifosato; Intoxicação; Saúde Pública.

\section{Analysis of poisoning by agricultural pesticides in Brazil between 2009 and 2014}

\begin{abstract}
In much of Brazilian agricultural production, pesticides have been widely used for crop protection and pest control. They are so used that there is much discussion about its abuse, and the consequences of its use for the human organism. Brazil has become the largest consumer of pesticides in the world, including herbicides, insecticides and fungicides. Organophosphate pesticides, especially glyphosates, are the most used in Brazilian productions and the target of several studies on their toxicity, since several pathologies are related to direct or indirect exposure to these products. This article aims to perform an analysis of pesticide use in Brazil, the main relationships with health and, through pesticide use data category agricultural use, to present data on the number of poisoning, aiming to detail how harmful continuous use pesticides contributes to public health spending. The methodology consisted of surveying open data from IBGE, SINAN and SINITOX to perform temporal analysis. It was found that the hazardous class III was the most used and glyphosate and its salts are the most applied active ingredients. Regarding poisoning, there was a decrease in case records, however, it is observed that there is still many underreporting in the country. It was also noted that for events such as these to be reduced, the implementation of public policies to encourage organic and agroecological production is indispensable, contributing to a better quality of life for all who work and consume the products derived from these productions.
\end{abstract}

Keywords: Glyphosate; Intoxication; Public health.

Topic: Epidemiologia e Saúde Ambiental

Reviewed anonymously in the process of blind peer.
Received: 15/08/2018

Approved: 22/08/2018
Jessyca Nunes Pereira (iD)

Universidade Federal do Oeste Pará, Brasil http://lattes.cnpq.br/1593352044319177 http://orcid.org/0000-0003-2433-784X

jessyca.nunes.p@gmail.com

Jéssica Ariana de Jesus Corrêa (iD)

Universidade Federal do Oeste do Pará, Brasil

http://lattes.cnpq.br/7180510909867481

http://orcid.org/0000-0002-2691-6020

jehssicorrea@yahoo.com.br

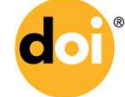

DOI: 10.6008/CBPC2179-6858.2018.006.0017
Referencing this:

PEREIRA, J. N.; CORRÊA, J. A. J.. Análise das intoxicações por agrotóxicos de uso agrícola no Brasil entre 2009 e 2014. Revista lberoAmericana de Ciências Ambientais, v.9, n.6, p.159-168, 2018. DOI: http://doi.org/10.6008/CBPC2179-6858.2018.006.0017 


\section{INTRODUÇÃO}

Com o aumento da população mundial, necessita-se, cada vez mais, de alimentos para atender essa demanda crescente. A agricultura é uma das formas de abastecimento mundial através de consumos internos e de exportação. Visando aumentar a produtividade de culturas agrícolas, o uso de agrotóxicos tem sido uma das formas amplamente usada no controle de pragas, principalmente no Brasil, onde as leis de fiscalização são deficientes. Outro fator que tem facilitado o aumento do uso de agrotóxicos no Brasil são as políticas governamentais implementadas a partir da década de 1960 como subsídios para plantar soja, cana-deaçúcar, milho e café para exportação (PEDLOWSKI et al., 2012).

A partir de 2008, o Brasil o tornou-se o maior consumidor de agrotóxicos mundial distribuídos em herbicidas (45\%), inseticidas (27\%) e fungicidas (28\%) (PEDLOWSKI et al., 2012). Seu consumo crescente representou, em 2009, nada menos do que 5,2kg de consumo por habitante (LONDRES, 2011). De acordo com Pignati et al. (2017), o uso indiscriminado ocorre principalmente devido a extensa área de plantio utilizados para agropecuária.

Entende-se por agrotóxicos todos os produtos que contém substâncias químicas destinadas contra a ação nociva de alguns tipos de seres vivos considerados praga em produções agrícolas, tais como insetos, ervas daninhas, fungos e bactérias (SELMI et al., 2014). Essa definição evidência a capacidade desses agentes de destruir vida, seja ela animal ou vegetal. De acordo com a regulamentação federal do Brasil, existe uma definição clara que regulamenta e trata sobre Agrotóxicos e afins:

[...] produtos e agentes de processos físicos, químicos ou biológicos, destinados ao uso nos setores de produção, no armazenamento e beneficiamento de produtos agrícolas, nas pastagens, na proteção de florestas, nativas ou plantadas, e de outros ecossistemas e de ambientes urbanos, hídricos e industriais, cuja finalidade seja alterar a composição da flora ou da fauna, a fim de preservá-las da ação danosa de seres vivos considerados nocivos, bem como as substâncias e produtos empregados como desfolhantes, dessecantes, estimuladores e inibidores de crescimento.

Os agrotóxicos englobam uma vasta gama de substâncias químicas, tais como os Organofosforados dos inseticidas e Glifosato dos herbicidas, porém, existem também alguns de origem biológica. A classificação varia de acordo com o tipo de praga que controlam, com a estrutura química das substâncias ativas e com os efeitos à saúde humana e ao meio ambiente (AGROFIT, 1998, citado por PERES et al., 2003), tais como fungicidas, herbicidas, inseticidas e outros grupos químicos, sendo os inseticidas o grupo químico de mais alta toxicidade.

Por sua quantidade de produtos quimicamente processados, os agrotóxicos são considerados pela Organização Mundial da Saúde - OMS (WHO, na sigla em inglês) como um fator de risco para a saúde, seja da população geral, que poderá ter acesso a alimentos sob contato de algum agente do produto; trabalhadores que tenham contato direto aos produtos químicos, assim como para o meio ambiente, que recebe uma determinada carga desses produtos (MALASPINA et al., 2011).

Quando se trata do meio ambiente, a grande preocupação está voltada para a dispersão das substâncias no meio ambiente através do ar e da água. Pela água, contamina o lençol freático através de escoamento do produto tanto para as águas superficiais como por lixiviação para o subterrâneo. Pelo ar, o 
vento carreia as partículas/resíduos para regiões ao redor do local que foi aplicado os agrotóxicos (PIGNATI et al., 2014; LONDRES, 2011).

Os agrotóxicos já foram vistos por trazer benefícios a saúde, sendo utilizados no combate de vetores de doenças infecciosas, tais como a malária e a dengue (OMS). Segundo Carvalho et al. (2008), estima-se que, até 1970, algo em torno de 2 bilhões de casos de malária tenham sido prevenidos pela campanha da OMS, salvando cerca de 15 milhões de vidas. Porém, as altas taxas de consumos de agrotóxicos na atualidade têm trazido preocupações quanto aos impactos que causam a saúde humana.

Os agrotóxicos podem trazer riscos à saúde pelo uso indiscriminado, falta de cuidado na manipulação e estocagem, mas principalmente nos trabalhadores dos setores que usam pesticidas, como a agricultura e a pecuária (CASSAL et al., 2014). Diversos estudos têm sido realizados com o intuito de verificar a saúde humana e sua relação com diferentes grupos de agrotóxicos (ABREU et al., 2014; SILVA et al., 2015).

A Agência Internacional de Pesquisa sobre Câncer (IRCA, na sigla em inglês) da OMS, classificou o herbicida Glifosato e os inseticidas Malathion e Diazinon como provavelmente cancerígeno para os seres humanos. De acordo com a Organização Mundial da Saúde, o uso intensivo de agrotóxicos representa um dos fatores de risco mais relevantes para a saúde humana, apresentando, em geral, como efeitos crônicos a esta exposição o desenvolvimento de câncer, malformação e danos para o sistema nervoso e endócrino.

Outro dado importante, informado pela Organização Internacional do Trabalho/Organização Mundial da Saúde (OIT/OMS), é que os agrotóxicos causam, anualmente, 70 mil intoxicações agudas e crônicas que evoluem para óbito, principalmente em trabalhadores de países em desenvolvimento (MALASPINA et al., 2011).

Nesse contexto, o Brasil, país em desenvolvimento, apresenta características relacionadas ao desenvolvimento agrícola que faz com que cada vez mais produtores usem diversos tipos de agrotóxicos, com o intuito de aumentar a produtividade das plantações através de combates as pragas. Contudo, ainda não há um controle de seu uso visando a saúde do meio ambiente e das pessoas que ficam expostas aos agentes nocivos dos agrotóxicos.

Diante disto, o objetivo deste trabalho é realizar uma análise do consumo de agrotóxicos no Brasil, as principais relações com a saúde e, através de dados de uso de agrotóxicos, categoria uso agrícola no país, apresentar dados sobre o número de intoxicação, visando detalhar o quão nocivo o uso contínuo de agrotóxicos contribui para os gastos com saúde pública.

\section{REVISÃO TEÓRICA}

\section{Classificação toxicológica e periculosidade ambiental por agrotóxicos}

Para se entender os efeitos na saúde e no meio ambiente, é necessário conhecer as classificações feitas para a toxicidade e periculosidade, os quais órgãos podem utilizar como padrões para monitoramento dos agrotóxicos no país. As classes estão divididas em seis, sendo representadas por algarismos romanos (quadro 1). Na ANVISA, a classificação é feita de acordo com seus efeitos agudos no organismo indo de 
extremamente tóxico (classe I) a pouco tóxico (classe IV). Esta classificação deve constar nas bulas e rótulos dos agrotóxicos (LONDRES, 2011) e sendo caracterizadas por cores para alertar o consumidor.

Quanto à classificação feita pelo Instituto Brasileiro de Meio Ambiente e Recursos Naturais Renováveis (IBAMA, 2017), qualifica os perigos ao meio ambiente levando em consideração entre outros fatores o transporte, persistência e bioconcentração dos ingredientes ativos, através da Avaliação do Potencial de Periculosidade Ambiental (PPA) com classificação de produto altamente perigoso (Classe I) e produto pouco perigoso (Classe IV).

Quadro 1: Classificação dos agrotóxicos.

\begin{tabular}{|l|l|l|l|}
\hline Classe & \multicolumn{1}{|c|}{$\begin{array}{c}\text { Toxicológico } \\
\text { (ANVISA) }\end{array}$} & \multicolumn{1}{|c|}{ Cor indicada na embalagem (ANVISA) } & Periculosidade Ambiental (IBAMA) \\
\hline I & Extremamente tóxico & Faixa vermelha & Produto Altamente Perigoso \\
\hline II & Altamente tóxico & Faixa amarela & Produto Muito Perigoso \\
\hline III & Moderadamente tóxico & Faixa azul & Produto Perigoso \\
\hline IV & Pouco tóxico & Faixa verde & Produto Pouco Perigoso \\
\hline
\end{tabular}

A partir desta classificação, é possível saber o risco que os trabalhadores estariam submetidos de acordo com determinados tipos de agrotóxicos. Embora, em exames, os agentes só podem ser detectados em até sete dias de sua aplicação pelo trabalhador, o conhecimento da classe do agrotóxico em sua embalagem pode ajudar a identificar a toxicidade.

Outra classificação é referente à exposição aos agrotóxicos, sendo as intoxicações consideradas aguda, subaguda e crônica. A aguda são aquelas intoxicações em que os sintomas aparecem algumas horas após o contato excessivo por curto período de tempo com produtos de extrema ou muitíssima toxidade. Já a intoxicação subaguda ocorre quando a exposição é moderada ou pequenas, menos intensa aos produtos químicos de classes altamente e pouco tóxicos, em que os sintomas aparecem lentamente com sintomas subjetivos por exemplo sonolências, mal-estar e outros. Enquanto a intoxicação crônica possui difícil determinação por seu surgimento tardio, que acarreta danos irreversíveis como paralisia e neoplasias devido à exposição por longos períodos de tempo aos agrotóxicos ou similares (OPAS, 1997).

\section{Impactos à Saúde}

Uma das grandes preocupações, quanto aos agrotóxicos, está voltada para a saúde humana, principalmente das pessoas que ficam expostas diretamente a eles, como os trabalhadores do campo ou da indústria. Em contato com o organismo, os agrotóxicos podem ser absorvidos através de contato com a pele, ingestão oral ou por inalação. Algumas doenças podem ser relacionadas aos efeitos crônicos dos agrotóxicos, tais como desregulação endócrina, doenças do fígado e rins, dermatites, câncer e outros. Porém, existe uma grande dificuldade em diagnosticar e registrar casos intoxicados por agrotóxicos no país (LONDRES, 2011).

De acordo com Cassal et al. (2014) são vários fatores que contribuem para o número de intoxicações por agrotóxicos, por exemplo, "a ampla utilização, o desrespeito às normas de segurança, a livre comercialização e a pressão exercida pelas empresas distribuidoras e produtoras". Além disso, a grande diversidade de produtos, com centenas de princípios ativos os quais as pessoas têm contato, só tem crescido 
através da síntese de novos princípios ativos e, assim, dificultando o diagnóstico e tratamento específico para cada intoxicação (SANTOS et al., 2015).

Os agrotóxicos que mais causam preocupação são os inseticidas organofosforados e carbamatos, os fungicidas ditiocarbamatos e os herbicidas fenoxiacéticos (2,4 D) e glifosato. Santos et al. (2015) fez uma revisão bibliográfica sobre intoxicações por organofosforados e verificou que a produção científica a respeito do tema cresceu a partir de 2000 e que os efeitos no organismo englobam uma variedade de sinais e sintomas, muito além daquelas visualizadas clinicamente, tais como casos de suicídio. Os pesticidas organofosforados são neurotóxicos e têm sido associados a um aumento dos problemas psiquiátricos, particularmente a depressão (FARIA et al., 2014).

\section{METODOLOGIA}

Trata-se de um estudo descritivo a partir de banco de dados secundários público que contém dados de agrotóxicos e intoxicações por agrotóxicos no Brasil no período de 2009 a 2014. Utilizou-se dados de agrotóxicos por classe de periculosidade, o consumo de agrotóxicos por área plantada e principais ingredientes ativos a partir da base de dados do Instituto Brasileiro de Geografia e Estatística (IBGE).

Quanto aos dados de intoxicação por agrotóxico, existem, no Brasil, dois sistemas que possuem série histórica de intoxicações no país. Dentre os sistemas, pode-se citar o SINAN (Sistema de Informação de Agravos de Notificação) e o SINITOX (Sistema Nacional de Informações Toxico-Farmacológicas). O SINAN faz parte do Ministério da Saúde, no qual, a partir de 2011, conforme estabelecido na portaria 104, de 25 de janeiro de 2011, foi incluída as intoxicações exógenas como de notificação compulsória. Já o SINITOX foi criado em 1980, e é vinculado à Fundação Oswaldo Cruz, notificando os casos de intoxicações de diferentes tipos como agrotóxicos/uso agrícola, agrotóxicos/uso doméstico, raticidas e produtos veterinários, medicamentos e outras categorias (REBELO et al., 2011). A partir dos dados do SINAN e SINITOX, fez-se análise temporal na categoria intoxicações por agrotóxicos/uso agrícola no período 2009 a 2014.

\section{RESULTADOS E DISCUSSÃO}

\section{Distribuição percentual dos agrotóxicos por classe de periculosidade ambiental no Brasil}

Ao se pensar em agrotóxico, logo se pensa nos prováveis danos que serão causados ao meio ambiente, acarretados por seu uso irrestrito e prolongado nas produções agrícolas. 0 gráfico 1 apresenta as porcentagens de agrotóxicos por classe de periculosidade no período 2009-2014. A utilização de agrotóxicos de classe III (Produto Perigoso) é bem acentuada em relação às outras classes apresentando valor médio de 61,81\% entre 2009 a 2014, com máximo de 64,1\% em 2012. No entanto, a classe II (Produto Muito Perigoso) esteve com média de $28,62 \%$ no período analisado. 


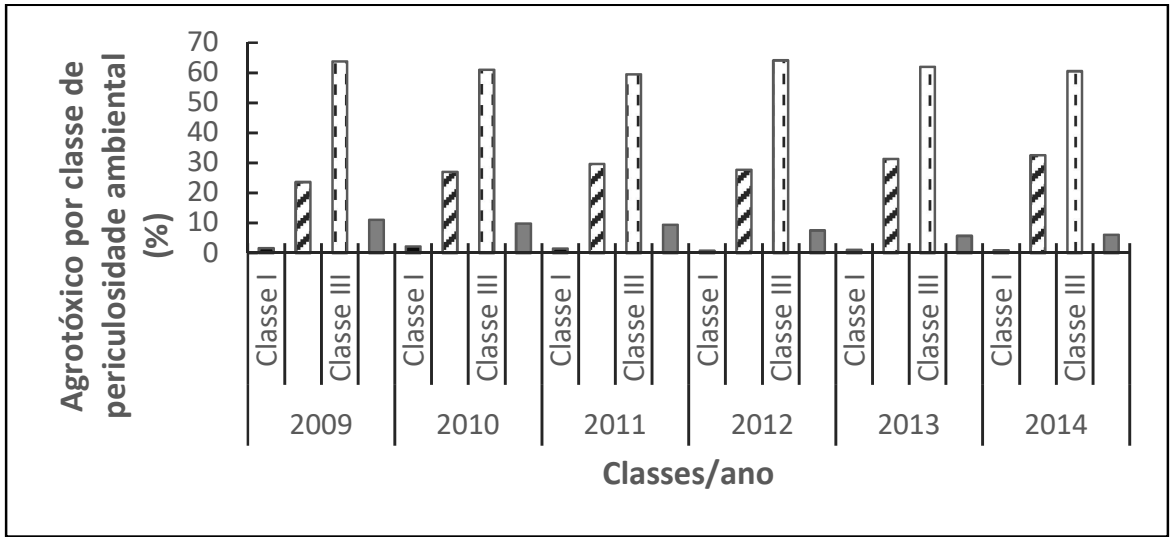

Gráfico 1: porcentagem de agrotóxicos no Brasil por classe de periculosidade ambiental no período de 2009 a 2014.

\section{Uso de Agrotóxicos no Brasil}

O consumo de agrotóxicos no Brasil, conforme gráfico 2, saiu de 3,2kg/ha em 2000 para 6,7kg/ha em 2014, mostrando o aumento significativo desse consumo no país. Na série histórica, o menor uso foi em 2002 com 2,7kg/ha, enquanto o maior consumo foi registrado em 2012 com 6,9kg/ha. De acordo com Pelaez et al. (2015), foi a partir dos anos 2000 que o Brasil tem apresentado maiores taxas de crescimento das importações mundiais de agrotóxicos. Com estas quantidades o Brasil tornou-se o maior consumidor de agrotóxicos do mundo (CASSAL et al, 2014; BELCHIOR et al., 2017).

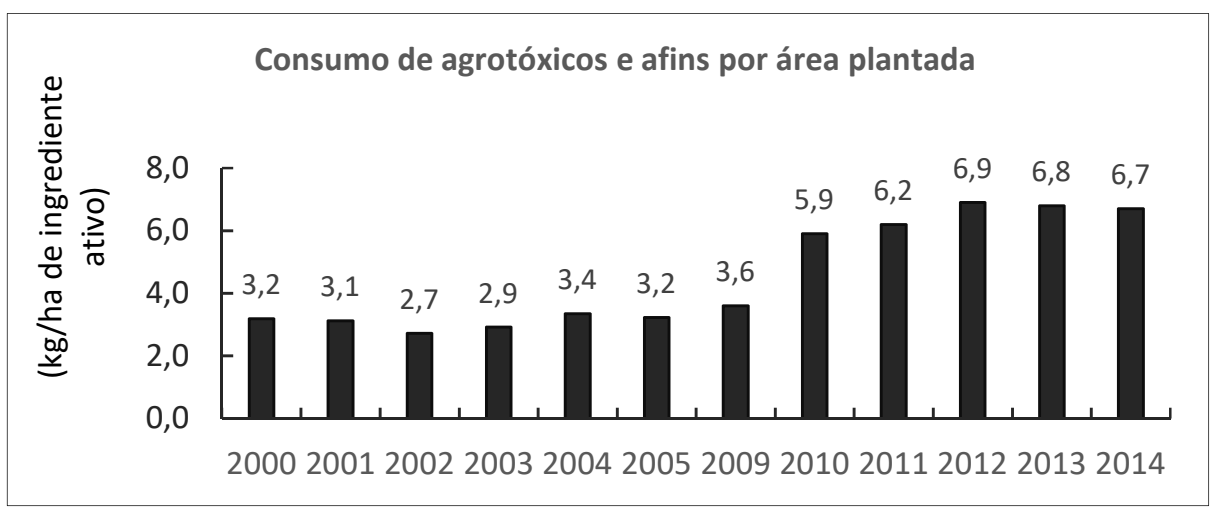

Gráfico 2: Consumo de agrotóxicos e afins por área plantada 2000 - 2014 no Brasil.

Segundo o IBGE, através do Indicadores de Desenvolvimento Sustentável (2014), do total de agrotóxicos consumidos no país, mais de $50 \%$ são herbicidas, seguidos pelos inseticidas, fungicidas e acaricidas. De acordo com o gráfico 3, o glifosato, principal ingrediente ativo dos herbicidas, foi o mais consumido no ano de 2014 com 193.947,9 toneladas de Ingrediente Ativo (Ton. IA). Observa-se que o uso acentuado de Glifosato pode ser considerado um dos maiores agravantes de intoxicação por agrotóxicos, uma vez que estudos relacionam sua utilização em casos de doenças crônicas, câncer e alterações hormonais. (AMARANTE JUNIOR et al., 2002). Quanto ao consumo de glifosato, esse alto consumo é preocupante uma vez que foi considerado como provável agente cancerígeno para os seres humanos. 


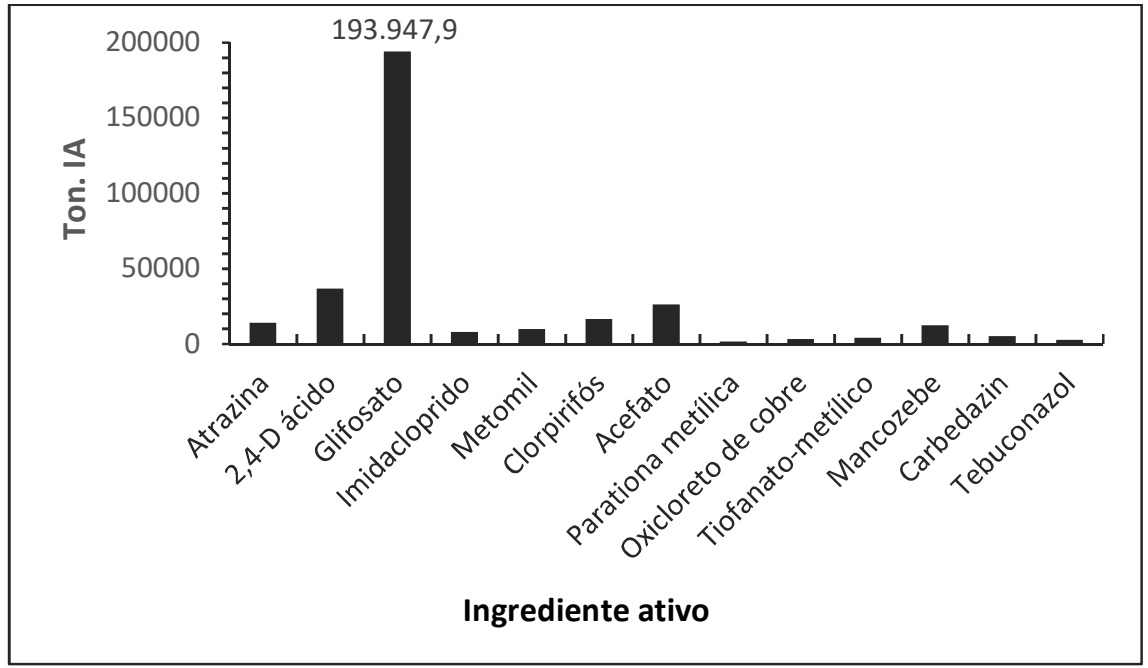

Gráfico 3: Consumo dos principais ingredientes ativos de agrotóxicos Brasil - 2014.

\section{Intoxicação por agrotóxicos no Brasil}

Embora exista no país diversos sistemas de notificação e registro sobe intoxicações provocadas por agrotóxicos, ainda existe muitos casos que não são notificados no país. 0 gráfico 4 apresenta dados do SINITOX de intoxicações humana por agrotóxicos de uso agrícola no período 2009-2014 totalizando 28.827 casos. Observa-se que há um decrescimento dos casos a partir de 2012, tendo um pico em 2013 com 3.096 casos.

Embora os dados de notificação tenham diminuído no sistema, o próprio SINITOX alerta para as subnotificações ocorridas e que, portanto, deve-se ter cuidado ao analisar esses dados, uma vez que os casos não têm diminuído, apenas foram deixados de serem notificados. É importante ressaltar a importância das notificações, pois contribuem para alertar às autoridades públicas sobre os riscos causados à exposição de agrotóxicos.

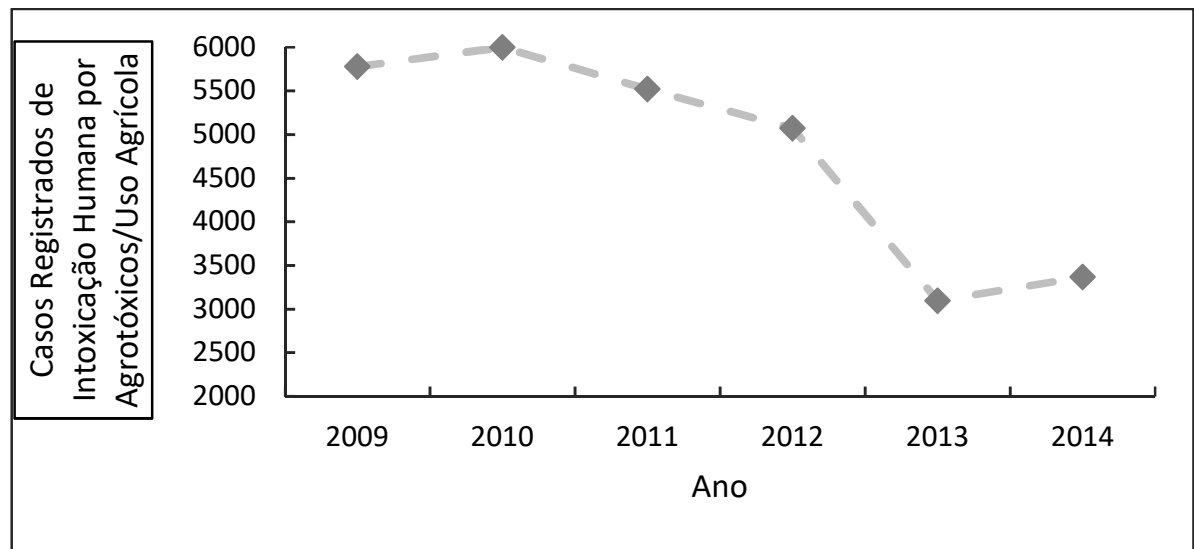

Gráfico 4: Casos Registrados de Intoxicação Humana por Agrotóxicos/Uso Agrícola no Brasil 2009 - 2014.

Em 2012, o Governo Federal lançou a Política Nacional de Agroecologia e Produção Orgânica (PNAPO - Decreto 7.794/2012), e em seguida, o Plano Nacional de Agroecologia e Produção Orgânica (PLANAPO), com o intuito de enfrentar o alto consumo de agrotóxicos nas produções brasileiras. Esse plano levou em conta a relação do uso direto dos agrotóxicos na agricultura e dramas socioambientais, marcados pela degradação da saúde e da qualidade de vida da população. Para tal, a Comissão Nacional de Agroecologia e 
Produção Orgânica (CNAPO), em 2014, formulou o PRONARA: Programa Nacional para a redução dos Agrotóxicos, constituído de seis eixos: (1) Registro; (2) Monitoramento; (3) Medidas Econômicas Financeiras; (4) Desenvolvimento de Alternativas; (5) Informação, Participação e Controle Social e (6) Formação e Capacitação.

O gráfico 5 apresenta dados de intoxicação exógena na Região Norte, onde 51,67\% dos casos registrados são no estado do Tocantins, onde as áreas produtivas têm aplicação de agrotóxicos. Pode-se observar também que estados, como Rondônia e Pará, também estão com altos índices de notificações, pois houve grande investimento para a produção agrícola, com a abertura das rodovias federais, tais como a BR319 (Porto Velho-Manaus), BR-153/010 (Belém-Brasília), BR-230 (Transamazônica), e BR-163 (CuiabáSantarém), principal rota de escoamento de grãos do estado do Mato Grosso para a exportação via Oceano Atlântico (CORREA et al., 2010).

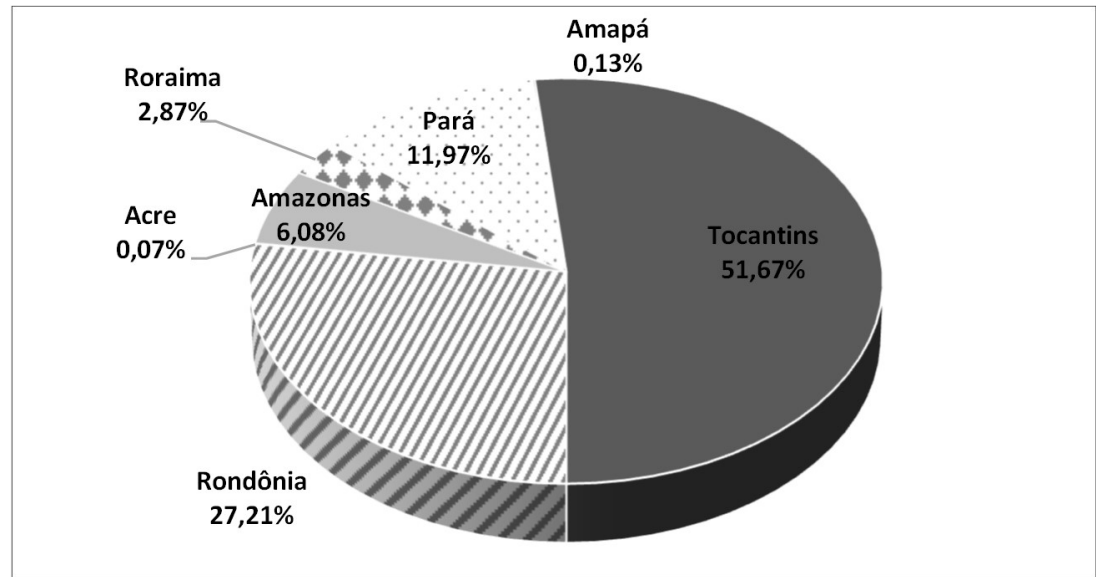

Gráfico 5: Intoxicações exógenas por agrotóxicos por região 2009- 2014.

Fez-se uma comparação dos números de casos confirmados com dados do SINAN e do SINITOX. De acordo com o gráfico 6, o número de notificações confirmados pelo SINAN teve variações no período analisado, contudo ainda são registros indispensáveis para esse monitoramento; já pelo SINITOX, o número de notificações despencou em 2012, mostrando que casos de intoxicação por agrotóxicos não são todos registrados, deixando as autoridades responsáveis sem maiores dados para acompanhamento dos mesmos. Embora tenha ocorrido variações nos dois sistemas no período analisado, observa-se que no somatório de casos estiveram bem próximas com o SINAN registrando 28.346 e o SINITOX, 28.827 casos.

Essas diferenças nos dois dados dos sistemas existem porque o SINITOX registra somente casos de intoxicações agudas (LONDRES, 2011). Além disso, o número de registros nos sistemas de acompanhamento é muito menor do que o número real de intoxicações - a própria Organização Mundial da Saúde reconhece que, para cada caso registrado de intoxicação por agrotóxicos, há 50 não notificados.

De acordo com Malaspina et al. (2011), as intoxicações agudas por agrotóxicos no Brasil já ocupavam a segunda posição dentre as intoxicações exógenas notificadas no Sistema do Ministério da Saúde (MS). Além disso, outro dado que aparece como significativo são os suicídios de trabalhadores rurais vinculados ao uso de agrotóxicos. Faria et al. (2014) reforçam em seu estudo a hipótese de que o uso de agrotóxicos e o envenenamento por pesticidas aumentam as taxas de suicídio, necessitando de mais estudos para entender 
e confirmar as relações causais. Os casos notificados apresentados não descrevem que tipo de situação estavam associadas aos agrotóxicos, tais como os tipos de hospitalização bem como as perdas e externalidades decorrentes das intoxicações. Porém, dão um indicativo da situação epidemiológica relacionada aos agrotóxicos.

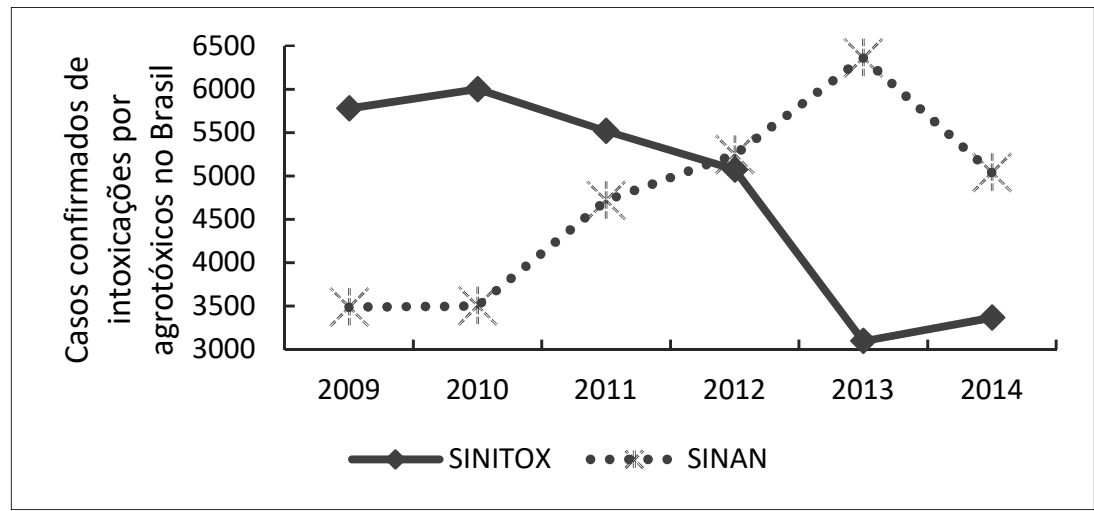

Gráfico 6: Casos confirmados de intoxicações no Brasil 2009-2014.

\section{CONSIDERAÇÕES FINAIS}

Diante do potencial risco ocasionado pelo uso dos agrotóxicos ao meio ambiente e principalmente à saúde do homem, muitas discussões têm sido voltadas para este tema nas últimas décadas. Verificou-se que algumas dessas substâncias causam anomalias ao ser humano. O glifosato, sendo o agrotóxico mais utilizado dentre os herbicidas, é o mais visado devido aos danos já apresentados em diversos estudos, que o relacionam a diversas patologias de acordo com seu grau de exposição, desde dermatites até o câncer.

Assim, este trabalho constatou que é preciso aprofundar ainda mais estudos e pesquisas que visem sanar as lacunas que existem quanto aos agrotóxicos, relacionando-os principalmente à saúde humana e qualidade de vida dos trabalhadores do setor agrícola e pecuarista, apresentando novas tecnologias para a redução de pragas em produção, aumento aos incentivos à produção agroecológica e orgânica e, principalmente, a aplicação das políticas públicas educacionais para a redução do uso de agrotóxicos, fundamental para a redução de casos de intoxicação no campo, setor de extrema importância para a economia do país.

\section{REFERÊNCIAS}

ABREU, P. H. B.; ALONZO, H. G. A.. Trabalho rural e riscos à saúde: uma revisão sobre o 'uso seguro' de agrotóxicos no Brasil. Ciência \& Saúde Coletiva, v.19, n.10, p.4197-4208, 2014.

AMARANTE JUNIOR, O. P.; SANTOS, T. C. R.; BRITO, N. M.; RIBEIRO, M. L.. Glifosato: propriedades, toxicidade, usos e legislação. Química Nova, Araraquara, v.25, n.4, p.589-593, 2002.

BELCHIOR, D. C. V.; SARAIVA, A. S.; LÓPEZ, A. M. C.; SCHEIDT, G. N.. Impactos de agrotóxicos sobre o meio ambiente e a saúde humana. Cadernos de Ciência \& Tecnologia, v.34, n.1, p.135-1551, 2017.
BRASIL. Decreto n.4.074 de 04 de janeiro de 2002. Regulamenta a Lei n.7802, de 11 de julho de 1989, que dispõe sobre a pesquisa, a experimentação, a produção, a embalagem e rotulagem, o transporte, o armazenamento, a comercialização, a propaganda comercial, a utilização, a importação, a exportação, o destino final dos resíduos e embalagens, o registro, a classificação, o controle, a inspeção e a fiscalização de agrotóxicos, seus componentes e afins, e dá outras providências. Brasília: DOU, 2002.

BRASIL. Decreto n.7.794 de 20 de agosto de 2012. Institui a Política Nacional de Agroecologia e Produção Orgânica. Brasília: DOU, 2012. 
BRASIL. Lei n.7.802 de 1 de julho de 1989. Dispõe sobre a pesquisa, a experimentação, a produção, a embalagem e rotulagem, o transporte, o armazenamento, a comercialização, a propaganda comercial, a utilização, a importação, a exportação, o destino final dos resíduos e embalagens, o registro, a classificação, o controle, a inspeção e a fiscalização de agrotóxicos, seus componentes e afins, e dá outras providências. Brasília: DOU, 1989.

BRASIL. PRONARA já: pela implementação imediata do Programa Nacional para a Redução de Agrotóxicos. Rio de Janeiro: PTA, 2015.

CARVALHO, R. C.; SOARES, W. L.; TEIXEIRA, F. C. P.; CARVALHO, W. S.. Expansão da Fronteira Agrícola e Intoxicação por Agrotóxicos: o caso da BR 163. ENCONTRO NACIONAL DA ANPPAS, 4. Anais. Brasília: ANPPAS, 2008.

CASSAL, V. B.; AZEVEDO, L. F.; FERREIRA, R. P.; SILVA, D. G.; SIMÃO, R. S.. Agrotóxicos: uma revisão de suas consequências para a saúde pública. REGET, v.18, n.1, p.437445, 2014.

CORREA, V. H. C.; RAMOS, P.. A precariedade do transporte público rodoviário brasileiro para o escoamento da produção de soja do Centro-Oeste: situação e perspectivas. Revista de Economia e Sociologia Rural, Brasília, v.48. n.2, p.447-472, 2010.

FARIA, N. M. X.; FASSA, A. G.; MEUCCI, R. D.. Association between pesticide exposure and suicide rates in Brazil. NeuroToxicology, v.45, p.355-362, 2014.

IBAMA. Instituto Brasileiro do Meio Ambiente e Recursos Naturais Renováveis. Avaliação do Potencial de Periculosidade Ambiental (PPA) de Agrotóxicos e afins. Brasília: IBAMA, 2017

IBGE. Instituto Brasileiro de Geografia e Estatística. Indicadores de Desenvolvimento Sustentável. Brasília: IBGE, 2014.

IRCA. International Agency for Research on Cancer. Evaluation of five organophosphate insecticides and herbicides. IARC Monographs, Paris, v.112, 2015.

LONDRES, F.. Agrotóxicos no Brasil: um guia para ação em defesa da vida. Rio de Janeiro: PTA, 2011.

MALASPINA, F. G.; ZINILISE, M. L.; BUENO, P. C.. Perfil epidemiológico das intoxicações por agrotóxicos no Brasil, no período de 1995 a 2010. Cadernos Saúde Coletiva, v.19, n.4, p.425-434, 2011.
OPAS. Organização Pan-Americana da Saúde. Manual de Vigilância da Saúde de Populações Expostas a Agrotóxicos. Brasília: OPAS, 1997.

PEDLOWSKI M. A.; CANELA, M. C.; TERRA, M. A. C.; FARIA, R. M. R. Modes of pesticides utilization by Brazilian smallholders and their implications for human health and the environment. Crop Protection, v.31, p.113-118, 2012.

PELAEZ, V. M.; SILVA, L. R.; GUIMARÃES, T. A; RI, F.; TEODOROVICZ, T.. A (des)coordenação de políticas para a indústria de agrotóxicos no Brasil. Revista Brasileira de Inovação, Campinas, v.14, p.153-178, 2015.

PERES, F.; MOREIRA, J. C.; DUBOIS, G. S.. Agrotóxicos, saúde e ambiente: uma introdução ao tema. É veneno ou Remédio?. Rio de Janeiro: FIOCRUZ, 2003.

PIGNATI, W. A.; LIMA, F. A. N. S.; LARA, S. S.; CORREA, M. L. M.; BARBOSA, J. R.; LEÃO, L. H. C.; PIGNATI, M. G.. Distribuição espacial do uso de agrotóxicos no Brasil: uma ferramenta para a Vigilância em Saúde. Ciência \& Saúde, v.2, n.10, p.3281-3293, 2017.

PIGNATI, W. A.; OLIVEIRA, N. P.; SILVA, A. M. C.. Vigilância aos agrotóxicos: quantificação do uso e previsão de impactos na saúde-trabalho-ambiente para os municípios brasileiros. Ciência \& Saúde Coletiva, v.19, n.12, p.46694678, 2014.

REBELO, F. M.; CALDAS, E. D.; HELIODORO, V. O.; REBELO, R. M.. Intoxicação por agrotóxicos no Distrito Federal, Brasil, de 2004 a 2007: análise da notificação ao Centro de Informação e Assistência Toxicológica. Ciência \& Saúde Coletiva, v.16, n.8, p.3493-3502, 2011.

SANTOS, J. A. T.; SELEGHIM, M. R.; NERILO, S. B.; FERNANDEZ, L. S.; OLIVEIRA, M. L. F.. Inseticidas Organofosforados e Intoxicação Humana: uma revisão da produção cientifica sobre o tema. SaBios: Revista de Saúde e Biologia, v.10, n.2, p.54-65, 2015.

SELMI, G. F. R.; TRAPÉ, A. Z.. Proteção da saúde de trabalhadores rurais: a necessidade de padronização das metodologias de quantificação da exposição dérmica a agrotóxicos. Caderno de Saúde Pública, Rio de Janeiro, v.30, n.5, p.952-960, 2014.

SILVA, J. F. S.; SILVA, A. M. C.; LIMA-LUZ, L.; AYDOS, R. D.; MATTOS, I. E.. Correlação entre produção agrícola, variáveis clínicas-demográficas e câncer de próstata: um estudo ecológico. Ciência \& Saúde Coletiva, v.20, n.9, p.2805-2812, 2015.

A CBPC - Companhia Brasileira de Produção Científica (CNPJ: 11.221.422/0001-03) detém os direitos materiais desta publicação. Os direitos referem-se à publicação do trabalho em qualquer parte do mundo, incluindo os direitos às renovações, expansões e disseminações da contribuição, bem como outros direitos subsidiários. Todos os trabalhos publicados eletronicamente poderão posteriormente ser publicados em coletâneas impressas sob coordenação da Sustenere Publishing, da Companhia Brasileira de Produção Científica e seus parceiros autorizados. Os (as) autores (as) preservam os direitos autorais, mas não têm permissão para a publicação da contribuição em outro meio, impresso ou digital, em português ou em tradução. 